\title{
Surgical management of symptomatic cavum septum pellucidum cysts: systematic review of the literature
}

\author{
Alexandre Simonin ${ }^{1,2}$ (D) Christopher R. P. Lind ${ }^{1,3}$ \\ Received: 2 March 2020 / Revised: 6 May 2020 / Accepted: 22 September 2020 / Published online: 19 December 2020 \\ (C) The Author(s) 2020
}

\begin{abstract}
Cavum septum pellucidum (CSP) and cavum vergae (CV) cysts are commonly found incidentally. They are usually asymptomatic but may present with symptoms related to obstructive hydrocephalus. There is no consensus about the management of symptomatic CSP and CV cysts. We present, to the best of our knowledge, the first systematic review of the different treatment options for symptomatic CSP and CV cysts. We conducted a literature review using PubMed database, searching for cases of symptomatic CSP and CV cysts managed surgically, and published until April 2019. Preoperative characteristics, surgical procedure, and postoperative outcome were analyzed using SPSS® software (Statistical Package for Social Sciences, IBM ${ }^{\circledR}$ ). We found 54 cases of symptomatic CSP and CV cysts managed surgically (34 males, 20 females, 1.7/1 male to female ratio). Mean age was $24.3 \pm 20.1$ years. The most common presentation was headaches (34 patients, $62 \%$ ), followed by psychiatric symptoms (27 patients, $49.1 \%$ ). Preoperative radiological hydrocephalus was present in 30 patients $(54.5 \%)$. The most common surgical procedure was endoscopic fenestration (39 patients, $70.9 \%$ ), followed by shunting (10 patients, $18.2 \%)$, open surgery (3 patients, 5.5\%), and stereotactic fenestration (1 patient, 1.8\%). Complete resolution of symptoms was achieved in 36 patients $(65.5 \%)$ and partial resolution in 7 patients (12.7\%), and symptoms were unchanged in 2 patients. The present review suggests that surgical treatment could provide resolution of the symptoms in most of the cases, regardless of the procedure performed. Although mean follow-up was short among the studies, recurrence rate was low.
\end{abstract}

Keywords Cavum septum pellucidum $\cdot$ Cavum vergae $\cdot$ Endoscopic fenestration

\section{Introduction}

Cavum septum pellucidum (CSP) is a common incidental finding, defined as a midline cerebrospinal fluid (CSF) space delimited superiorly by the crus of the fornices and inferiorly by the tela choroidea of the third ventricle [1]. It is anatomically distinct from cavum vergae (CV) which is a CSF space extending posteriorly to the columns of the fornix. However, CSP and $\mathrm{CV}$ cysts are used interchangeably in the literature and may coexist in many cases [1-5]. In this manuscript, we will use the

Alexandre Simonin

alexandresimonin21@gmail.com

1 Department of Neurosurgery, Sir Charles Gairdner Hospital (SCGH), Level 1, Nedlands, WA 6009, Australia

2 Department of Clinical Neurosciences, Service of Neurosurgery, Lausanne University Hospital (CHUV), Lausanne, Switzerland

3 Medical School, University of Western Australia, Perth, WA, Australia terminology cavum septum pellucidum and vergae (CSP and CV) cyst. Although considered as an incidental finding by most neurosurgeons, they may present with symptoms related to hydrocephalus, like headaches, nausea or vomiting, loss of consciousness, or psychiatric disturbances [1-10]. There is no consensus about the management of symptomatic CSP and CV cysts, and various procedures (endoscopic or stereotactic fenestration, shunting, open fenestration, etc.) have been proposed [1, $3-5,8,11-13]$. Although most of the authors report good results, there is currently no review of the literature concerning the surgical management of this controversial condition. The aim of the present study is to review the preoperative characteristics, surgical procedures, and postoperative outcome of symptomatic CSP and CV cysts treated surgically and reported in the literature.

\section{Methods}

We conducted a literature review using PubMed database, searching for cases of symptomatic CSP and CV cysts 
managed surgically and published until April 2019. We used the search term "cavum septum pellucidum" to perform the research. Three hundred and forty-five articles were found, and we considered 37 articles eligible for our study [1-35] based on the criteria that the management of a symptomatic cyst was detailed in the article. Twenty-three articles reported cases managed surgically $[1-3,6,8,10,14,15,17,18,21-27$, 32-35], and a total of 54 patients were finally identified. We created a database using Microsoft Excel ${ }^{\circledR}$ and SPSS ${ }^{\circledR}$ softwares (Statistical Package for Social Sciences, IBM®). Preoperative characteristics (Table 1) were summarized with patient gender, age, clinical presentation, and presence of preoperative hydrocephalus. Management (type of surgical procedure), clinical outcome, radiological outcome, complications, follow-up, and recurrences were also recorded (Table 2). We used SPSS ${ }^{\circledR}$ software (Statistical Package for Social Sciences, IBM ${ }^{\circledR}$ ) descriptive statistics to analyze age and follow-up means and standard deviation. Frequency statistics were used to analyze gender (male/female), headaches (yes/no), psychiatric symptoms (yes/no), loss of consciousness (yes/no), seizures (yes/no), nausea/vomiting (yes/no), papilledema (yes/no), preoperative hydrocephalus (yes/no), surgical procedure (endoscopic, stereotactic, open surgery, shunting), type of endoscopic procedure (frontal, parietal, transcavum), shunt (definitive, transient, or none), complications (yes/no), clinical outcome (resolution of symptoms/improvement/unchanged/died/unknown), radiological outcome (significant decrease of the cyst/persistent enlargement/unknown), and recurrences (yes/no). We used an unpaired Student's $t$ test to look for significant differences in clinical presentation and outcome between male and female patients. Unpaired Student's $t$ test was used to look for independent variables between males and females and between children and adults and to identify independent predictors of good clinical outcome (resolved of improved symptoms), recurrence, and good radiological outcome (decrease of the cyst size on postoperative imaging).

\section{Results}

We found 54 cases of symptomatic CSP and CV cysts managed surgically ( 34 males, 20 females, 1,7/1 male to female ratio). There were 23 children and 21 adults (18 years old). Patients' characteristics are presented in Table 1. Mean age was $24.3 \pm 20.1$ years. The most common presentations were headaches ( 34 patients, $62 \%$ ), followed by psychiatric symptoms (27 patients, $49.1 \%$ ). Preoperative radiological hydrocephalus was present in 30 patients $(54.5 \%)$. Different surgical approaches were performed and are detailed in Fig. 1. The most common surgical procedure was endoscopic fenestration (39patients, 70.9\%), followed by shunting (10 patients, $18.2 \%$ ), open surgery (3 patients, $5.5 \%$ ), and stereotactic fenestration (1 patient, 1.8\%). Complete resolution of symptoms was achieved in 36 patients $(65.5 \%)$ and partial resolution in 7 patients (13\%), and symptoms were unchanged in 2 patients. Complications occurred in 5 patients $(9.1 \%)$, including 1 death. Recurrence of the cyst occurred in 2 patients $(5 \%)$. Mean follow-up was $2.8 \pm 4.3$ months. Comparison between children $(n=23)$ and adults $(n=21)$ revealed statistically significant differences in clinical presentation. There were more headaches in adults (89\%) than children (48\%), $p=$ 0.004 . Psychiatric disturbances were more common in children (76\%) than adults (33\%), $p=0.006$. The other presenting features did not statistically differ between the two age groups, neither the surgical outcome. Between males $(n=34)$ and females $(n=20)$, only loss of consciousness almost reached significance (only $8 \%$ of females, but $33 \%$ of males presented with loss of consciousness, $p=0.053$ ). Independent predictors of good clinical outcome (resolution or improvement of symptoms) were preoperative radiological hydrocephalus ( $96 \%$ in the good outcome group vs $4 \%$ in the bad outcome group, $p<0.0001$ ), presence of nausea/vomiting (27\% in the good outcome vs $0 \%$ in the bad outcome group, $p=0.003$ ), and papilledema (13\% in the good outcome group, vs $0 \%$ in the bad outcome group, $p=0.04)$. Open surgery/shunting procedures $(n=13)$ were associated with poor clinical outcome $(p=0.02)$ compared with endoscopic/stereotactic procedures $(n=40)$. There were no differences between types of endoscopic or stereotactic procedures performed (frontal, parietal, transcavum fenestrations, stereotactic or endoscopic). Recurrence $(n=2)$ was associated with older age (mean = $52 \pm 13$ years old $)$ than the group without recurrence $(n=52)$ (mean $=22 \pm 17$ years old), $p=0.016$. Shunt procedures were also associated with recurrence ( $50 \%$ of recurrence, $p=0.027$ ) comparing with the other procedures. Good radiological outcome (decrease of the cyst size) was achieved in all patients, except one (who died). This mortality was attributed to bleeding and infection related to a surgically placed external shunt.

\section{Discussion}

Cavum septum pellucidum and cavum vergae cysts are potential space filled with CSF between the leaflets of the tela choroidea of the third ventricle [1]. As stated in the introduction, CSP is delimited superiorly by the crus of the fornices and inferiorly by the tela choroidea of the third ventricle [1]. $\mathrm{CV}$ extends posteriorly to the columns of the fornix. Finally, cavum velum interpositum (CVI) is also anatomically distinct, because it surrounds the internal cerebral veins, whereas $\mathrm{CV}$ and CSP lie above them. As CSP and CV cysts were mostly used interchangeably in the literature, we decided to study them together. Usually considered as an incidental finding, and mostly managed conservatively, they may however present with symptoms. Wang et al. [34] found that 22 of 54,000 
Table 1 Preoperative characteristics, $n=39$

Patient Sex $\begin{aligned} & \text { Age Clinical presentation } \\ & \text { (years) }\end{aligned}$

Duration of symptoms (months)
Preoperative Reference hydrocephalus

\begin{tabular}{|c|c|c|c|c|c|}
\hline Male & 3 & Developmental delay, irritability, macrocephaly & & Yes & 1) \\
\hline Female & 13 & Psychiatric symptoms (eating disorder, mood disturbances, anxiety) & & No & 1) \\
\hline Male & 42 & Postural headaches, disorders of consciousness & & 48 & 2) \\
\hline Male & 61 & Postural headaches, disorders of consciousness, dizziness, ataxia & & & 2) \\
\hline Male & 46 & Postural headaches, disorders of consciousness & & & 2) \\
\hline Female & 60 & Postural headaches & & No & 2) \\
\hline Male & 0.5 & Developmental delay & & Yes & 2) \\
\hline Male & 12 & Headaches, vomiting & 24 & Yes & 3) \\
\hline Female & 13 & Macrocephaly, irritability & 24 & No & 3) \\
\hline Female & 26 & Headaches, blurring of vision & & Yes & 3) \\
\hline Male & 4.5 & Impaired mental function with vomiting, seizures & & & 20) \\
\hline Female & 1.9 & Impaired mental function with hydrocephalus, papilledema, paraparesis & 12 & Yes & 22) \\
\hline Female & 2.9 & Impaired mental state with hydrocephalus and ataxic gait & & & 23) \\
\hline Male & 6 & Behavioral disturbance with impaired gait & & & 24) \\
\hline Male & 1.5 & Hydrocephalus and dyspnea with mental changes & & & 25) \\
\hline Male & 13 & Headaches, dizziness, behavioral disturbance & & Yes & 26) \\
\hline Female & 23 & Headaches, behavioral disturbance & 12 & Yes & 26) \\
\hline Female & 19 & Epilepsy & 2 & Yes & 26) \\
\hline Male & 60 & Headaches, unstable gait, papilledema & 36 & Yes & 26) \\
\hline Female & 32 & Headaches, dizziness, papilledema, behavioral disturbance & 12 & Yes & 26) \\
\hline Male & 18 & Epilepsy, behavioral disturbance & 24 & Yes & 26) \\
\hline Male & 34 & Headaches, dizziness, epilepsy, behavioral disturbance & 30 & Yes & 26) \\
\hline Male & 3 & Headaches, vomiting & 26 & Yes & 26) \\
\hline Male & 8 & Headaches, behavioral disturbance & 16 & Yes & 26) \\
\hline Male & 3 & Signs of hydrocephalus & 12 & Yes & 26) \\
\hline Male & 8 & Headaches, behavioral changes, syncopal attacks & & Yes & 27) \\
\hline Male & 0.5 & Headaches, syncopal episodes, neuropsychological disturbances & & Yes & 28) \\
\hline Male & 42 & headaches, syncopal episodes, impairment of memory & & & 28) \\
\hline Male & 17 & Uncontrolled seizures, cognitive impairment & & Yes & 6) \\
\hline Female & 24 & Headaches, vomiting, mental dulling, drowsiness & & Yes & 8) \\
\hline Male & 44 & Postural headaches & & Yes & 10) \\
\hline Male & 14 & Headaches, vomiting, syncope, decreased concentration and attention & & & 14) \\
\hline Male & 12 & Headaches, disorders of consciousness, rigidity & & Yes & 15) \\
\hline Male & 44 & Sudden headaches, loss of consciousness & & Yes & 17) \\
\hline Male & 17 & Wilson disease, seizures, cognitive impairment & & Yes & 18) \\
\hline Male & 9 & Motor and mental retardation, seizures & & No & 19) \\
\hline Male & 31 & Intermittent headaches, nausea, vomiting & & Yes & Our series \\
\hline Female & 24 & Postural headaches, nausea & & Yes & Our series \\
\hline Female & 22 & Headaches, dizziness, nausea, vertigo & & Yes & Our series \\
\hline Female & 22.5 & Explosive headache & & 24 & 34) \\
\hline Male & 46.8 & Explosive headache, nausea, vomiting, behavioral disturbance & & 4 & 34) \\
\hline Male & 31 & Explosive headache & & 9 & 34) \\
\hline Male & 2 & $\begin{array}{l}\text { Progressive macrocephaly, unclosed anterior fontanelle, delayed psychomotor } \\
\text { development }\end{array}$ & & 6 & 34) \\
\hline Male & 13.5 & $\begin{array}{l}\text { Progressive behavioral deterioration, uncontrollable mood swings, declining school } \\
\text { performance }\end{array}$ & & 23 & 34) \\
\hline Female & 69 & Progressive deterioration of gait, quadriparesis, headache & & 8 & 34) \\
\hline Female & 9 & $\begin{array}{l}\text { Learning difficulties, unable to concentrate, emotional changes, memory loss, } \\
\text { epilepsy, vomiting, loss of consciousness, declining school performance }\end{array}$ & & 72 & 34) \\
\hline Female & 22.8 & Headache, vertigo, visual disturbance, memory loss & & 17 & 34) \\
\hline Male & 12.1 & Explosive headache accompanying collapse, visual disturbance & & 6 & 34) \\
\hline Male & 33 & Progressive headache & & 60 & 34) \\
\hline Female & 11 & Progressive headache, mental retardation & 60 & Yes & 35) \\
\hline Female & 36 & Disturbance of eye-movements, diplopia & 0.25 & Yes & 35) \\
\hline Male & 63 & Diplopia, headaches, confusion & 24 & Yes & 35) \\
\hline Female & 82 & Short-term memory deficits and gait instability, falls, urinary incontinence & & Yes & 37) \\
\hline Female & 41 & Short-term memory deficits and gait instability, falls, urinary incontinence & & Yes & 37) \\
\hline
\end{tabular}




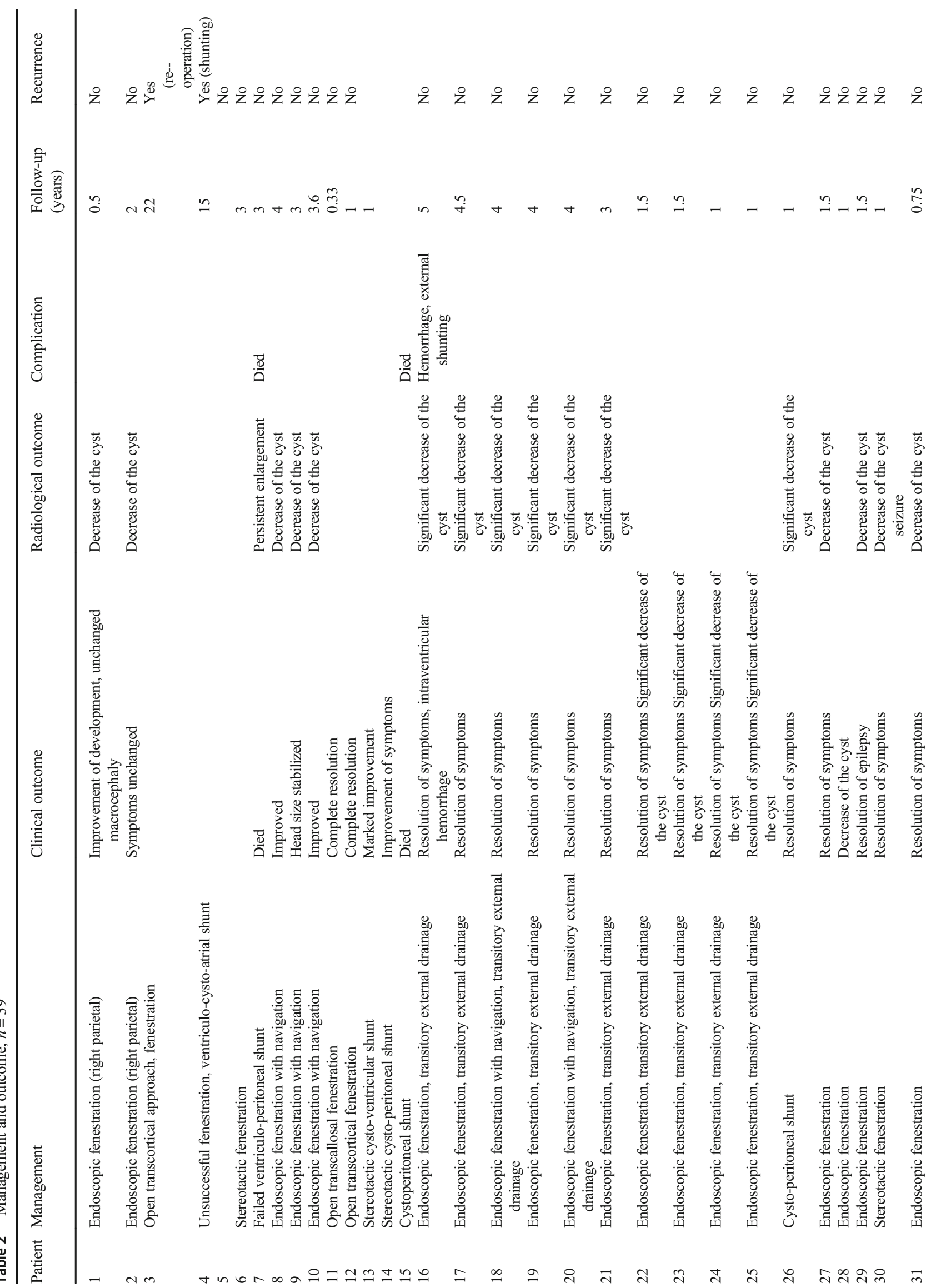




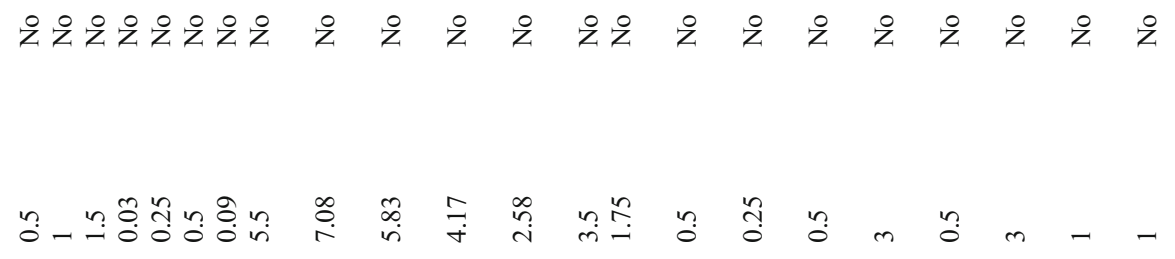

₹

咅弯

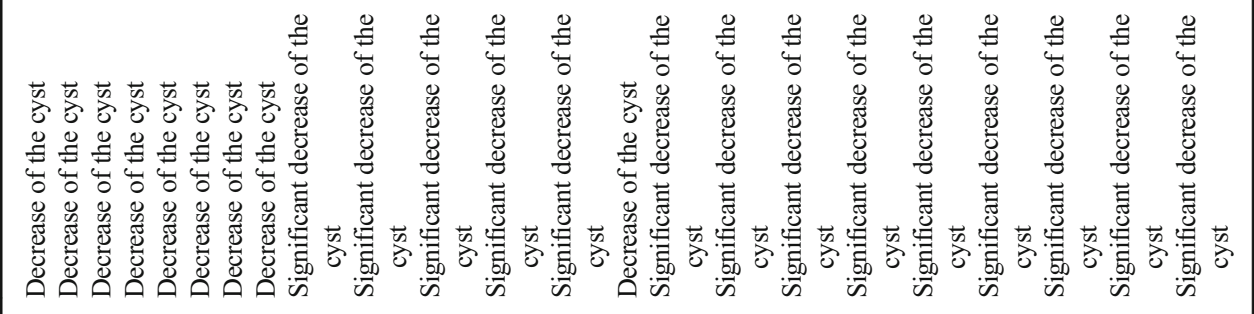

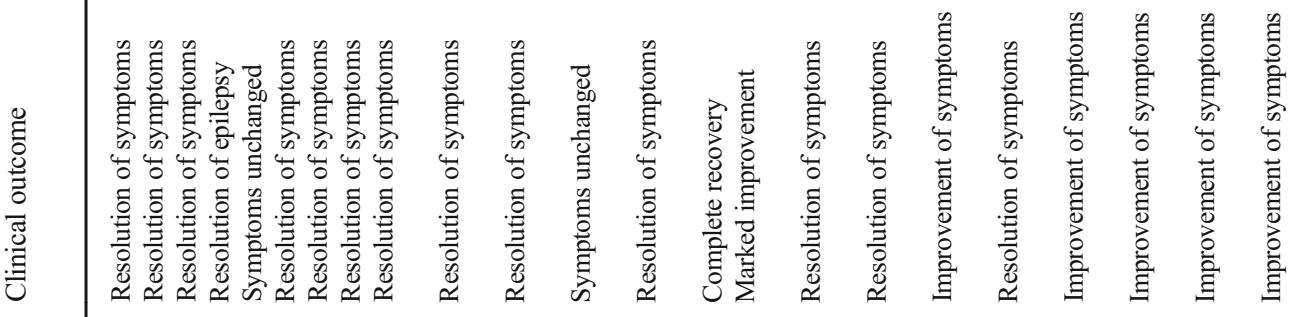

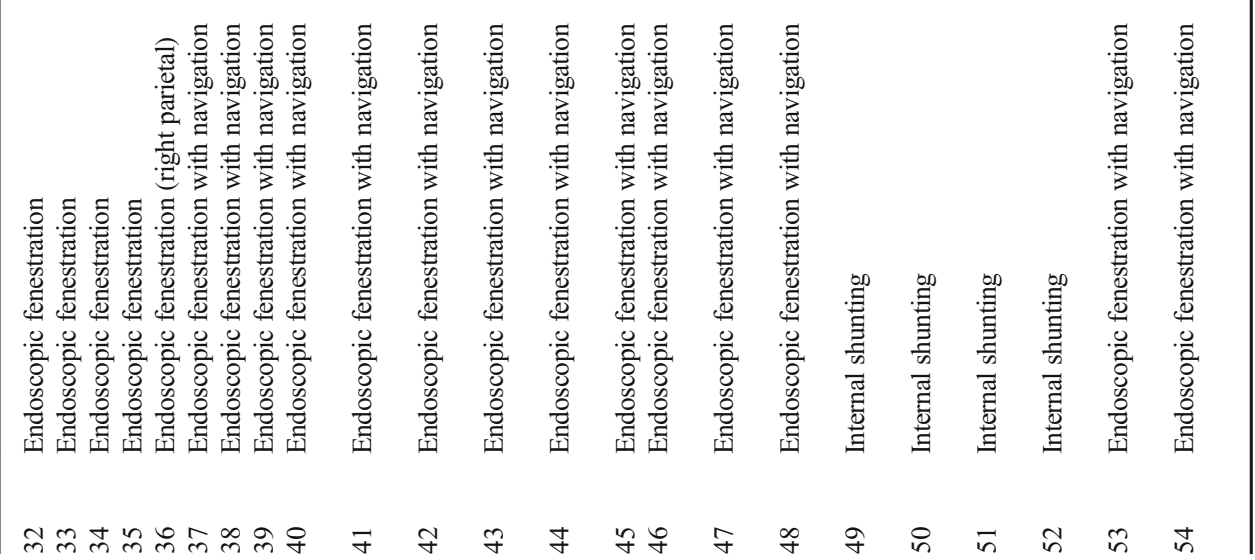


Fig. 1 Flowchart showing the different approaches used in the literature review cases

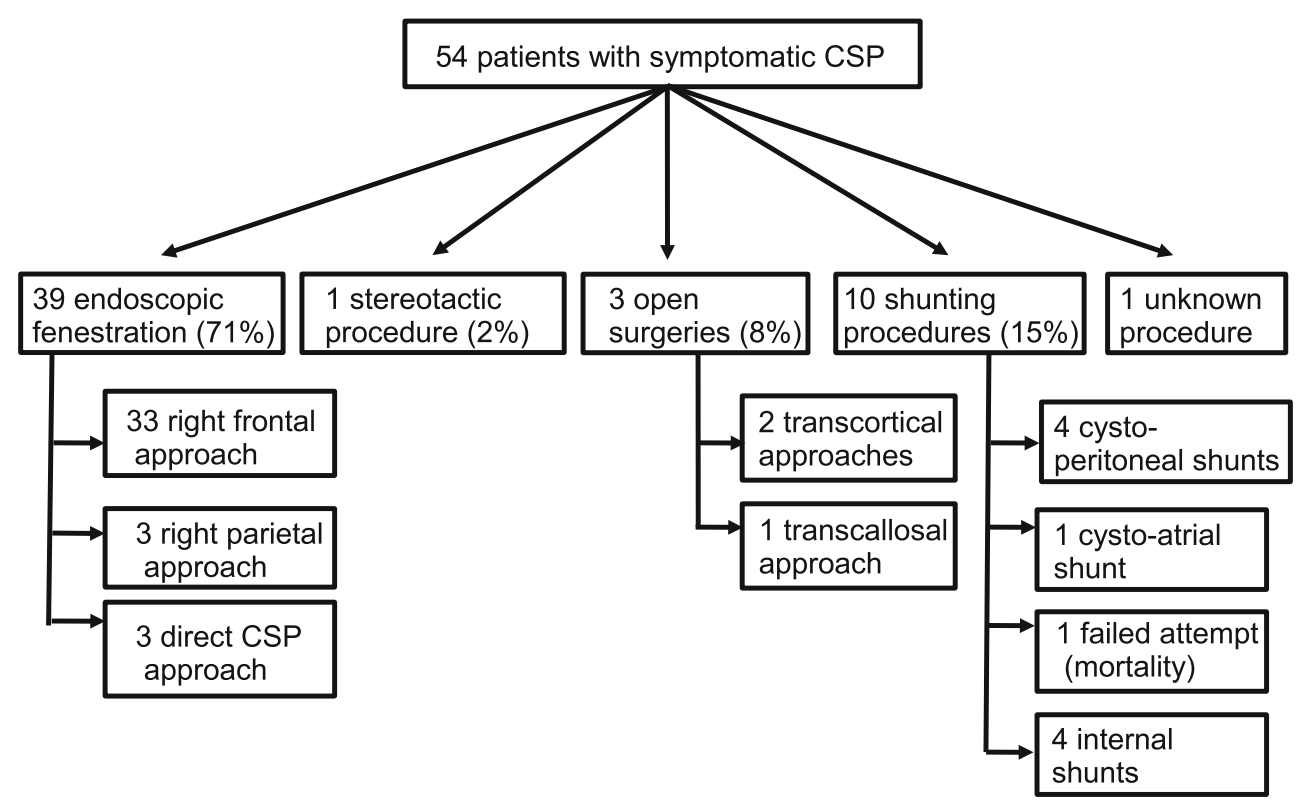

patients $(0.04 \%)$ having an MRI had a dilated cyst of the CSP. According to Shaw et al. (1969) [2], cysts may be classified into two groups: incidental (asymptomatic) or pathological (symptomatic). The incidence of symptomatic CSP and CV cysts is hard to define. To the best of our knowledge, the current paper is the first review of the literature concerning symptomatic CSP and CV cysts. Symptomatic CSP and CV cysts are rare and usually present with specific symptoms, such as headaches, behavioral disorders, or cognitive impairment [4]. However, there may be signs and symptoms related to hydrocephalus secondary to the occlusion of the Monroe foramina by the leaflets of the cyst $[4,26]$. Moreover, most of the cases reported in the literature presented with radiological evidence of hydrocephalus, as well as regression of the cyst on postoperative imaging ${ }^{1-}$

[31]. Regarding the size of the cyst, several authors argue that a CSP is defined as a cyst having a width of $10 \mathrm{~mm}$ or more between the ventricles [1-5, 19-25]. It may not be reasonable to consider a surgical fenestration for smaller cysts. In our review, the main presenting symptom was headaches (67\%), which may be related to the potential implication of hydrocephalus in the development of a symptomatic CSP and $\mathrm{CV}$ cyst. Interestingly, psychiatric symptoms, mainly behavioral disturbances, were the second most common finding $(56 \%)$. We use the generic term "psychiatric symptoms," because of the heterogeneity of symptoms reported in the literature: behavioral changes, eating disorder, mood disturbances, and anxiety have been reported by several authors $[1,3$, 5-10]. These symptoms may be difficult to correlate with CSP and CV cysts. However, an improvement was observed in most of the cases, which may suggest that stretching of midline structures by the cyst could be related to psychiatric disturbances [1]. Our results show that preoperative hydrocephalus was present in most of the patients and was an independent predictor of good clinical outcome. Absence of hydrocephalus at presentation may suggest that the correlation between the cyst and the presenting symptoms is unclear. Conservative management could be offered in those cases, although some reports suggest that symptoms may be improved $[1,3,5,6]$. Most of the papers reviewed did not specify the duration of symptoms for each patient. However, most of the cases had 1 month to 3 years of symptoms before fenestration [25]. Different procedures have been proposed in the papers we reviewed. The most common approach was endoscopic fenestration of the cyst. This involves a burr-hole craniotomy, most commonly performed in the right frontal region, to fenestrate the cyst to the lateral ventricle. However, other approaches have been described, including parietal cystostomy, or direct transcavum interforniceal endoscopic fenestration, as described by the authors of this manuscript elsewhere (in press, Operative Neurosurgery). Preoperative and postoperative images of a patient that benefited from this procedure are illustrated in Fig. 2. Endoscopic and stereotactic approaches may be superior to open or shunting procedures. However, there was no statistically significant difference between the types of endoscopic approach performed regarding the outcome, complications, or recurrence rate. Most of the authors recommend an endoscopic cyst fenestration through a frontal burr-hole, with neuronavigation. Regardless of the technique, most of the cases presented with a reduction of the cyst size after fenestration (Table 2). We advocate a transcavum interforniceal approach to restore more anatomically the flow of CSF to the third ventricle, because it creates a communication between the lateral ventricles and the third 

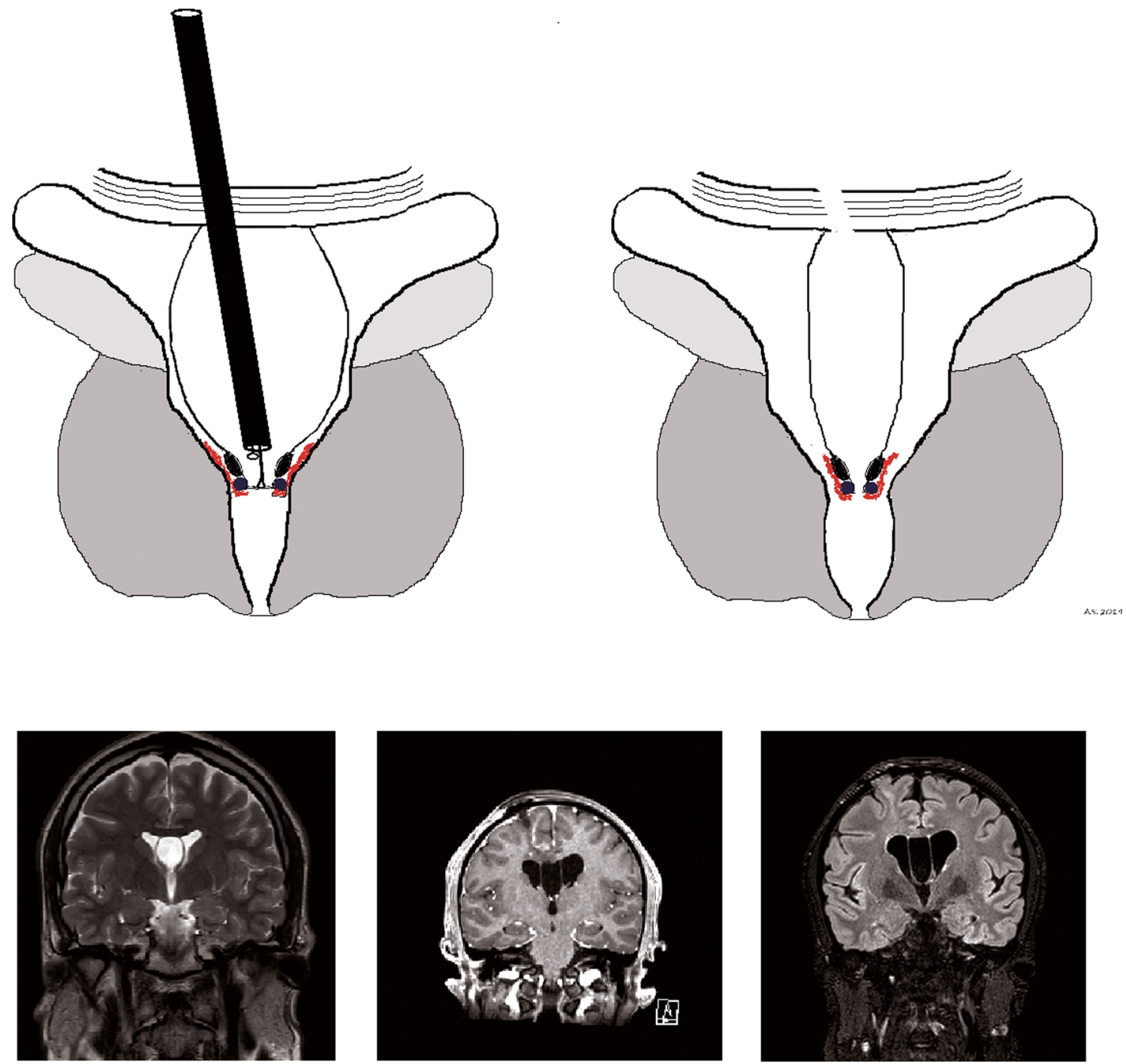

Fig. 2 Preoperative (left) and postoperative (right) MRI of a patient with a cavum septum pellucidum cyst fenestrated endoscopically. T2 coronal reconstructions (upper panels) and $\mathrm{T} 1$ sagittal reconstructions (lower panels)

ventricle (like the foramen of Monro). Moreover, it avoids midline structures (fornices, internal cerebral veins) that are displaced laterally by the cyst.

\section{Conclusion}

This review of the literature suggests that surgical treatment may be an option for the treatment of symptomatic CSP and CV cysts. Resolution or improvement of the symptoms was achieved in most of the cases. Endoscopic or stereotactic fenestrations seem to be superior to open or shunting procedures, with better clinical outcome and less recurrence. Operative management may be considered for symptomatic CSP and $\mathrm{CV}$ cysts, especially when associated with hydrocephalus.
Funding Open access funding provided by University of Lausanne.

\section{Compliance with ethical standards}

Ethical approval This manuscript is in accordance with the ethical standards of the Sir Charles Gairdner Hospital Human Research Ethics Committee and with the 1964 Helsinki declaration and its later amendments or comparable ethical standards.

Informed consent was given by both patients operated in the Sir Charles Gairdner Hospital.

Open Access This article is licensed under a Creative Commons Attribution 4.0 International License, which permits use, sharing, adaptation, distribution and reproduction in any medium or format, as long as you give appropriate credit to the original author(s) and the source, provide a link to the Creative Commons licence, and indicate if changes were made. The images or other third party material in this article are included in the article's Creative Commons licence, unless indicated otherwise in a credit line to the material. If material is not included in the article's 
Creative Commons licence and your intended use is not permitted by statutory regulation or exceeds the permitted use, you will need to obtain permission directly from the copyright holder. To view a copy of this licence, visit http://creativecommons.org/licenses/by/4.0/.

\section{References}

1. Tong CK, Singhal A, Cochrane DD (2012) Endoscopic fenestration of cavum velum interpositum cysts: a case study of two symptomatic patients. Childs Nerv Syst 28(8):1261-1264

2. Silbert PL, Gubbay SS, Vaughan RJ (1993) Cavum septum pellucidum and obstructive hydrocephalus. J Neurol Neurosurg Psychiatry 56(7):820-822

3. Udayakumaran S, Onyia CU, Cherkil S (2017) An analysis of outcome of endoscopic fenestration of cavum septum pellucidum cyst more grey than black and white? Pediatr Neurosurg 52(4):225-233

4. Tamburrini G, Mattogno PP, Narenthiran G, Caldarelli M, Di Rocco C (2017) Cavum septi pellucidi cysts: a survey about clinical indications and surgical management strategies. Br J Neurosurg 31(4):464-467

5. Nishijima Y, Fujimura M, Nagamatsu K, Kohama M, Tominaga T (2009) Neuroendoscopic management of symptomatic septum pellucidum cavum vergae cyst using a high-definition flexible endoscopic system. Neurol Med Chir (Tokyo) 49(11):549-552

6. Rahman A, Haque SU, Bhandari PB, Alam S (2017) Was cavum septum pellucidum the cause of intractable seizure in a 17-year-old boy with Wilson disease? World Neurosurg 105:1035.e5-1035.e10

7. Koerte IK, Hufschmidt J, Muehlmann M, Tripodis Y, Stamm JM, Pasternak O, Giwerc MY, Coleman MJ, Baugh CM, Fritts NG, Heinen F, Lin A, Stern RA, Shenton ME (2016) Cavum septi pellucidi in symptomatic former professional football players. J Neurotrauma 33(4):346-353

8. Pierfrancesco M, Stefania F, Carmelo M, Umberto G (1995) Symptomatic cyst of the septum pellucidum treated by stereotactic intraventricular drainage. Stereotact Funct Neurosurg 64(3):134 138

9. Tubbs RS, Krishnamurthy S, Verma K, Shoja MM, Loukas M, Mortazavi MM, Cohen-Gadol AA (2011) Cavum velum interpositum, cavum septum pellucidum, and cavum vergae: a review. Childs Nerv Syst 27(11):1927-1930

10. Bell RS, Vo AH, Dirks MS, Mossop C, Gilhooly JE, Cooper PB, Razumovsky AY, Armonda RA (2010) Transcranial Doppler ultrasonography identifies symptomatic cavum septum pellucidum cyst: case report. J Vasc Interv Neurol 3(1):13-16

11. Van Wagenen WP, Aird RB (1934) Dilatations of the cavity of the septum pellucidum and cavum vergae: report of cases. J Cancer Res 20:(3)

12. Souweidane MM, Hoffman CE, Schwartz TH (2008) Transcavum interforniceal endoscopic surgery of the third ventricle. J Neurosurg Pediatr 2(4):231-236

13. Tirakotai W, Schulte DM, Bauer BL, Bertalanffy H, Hellwig D (2004) Neuroendoscopic surgery of intracranial cysts in adults. Childs Nerv Syst 20(11-12):842-851

14. Borha A, Ponte KF, Emery E (2012) Cavum septum pellucidum cyst in children: a case-based update. Childs Nerv Syst 28(6):813819

15. Giussani C, Fiori L, Trezza A, Riva M, Sganzerla EP (2011) Cavum veli interpositi: just an anatomical variant or a potentially symptomatic CSF compartmentalization? Pediatr Neurosurg 47(5): 364-368

16. Chen JJ, Chen DL (2013) Chronic daily headache in a patient with cavum septum pellucidum and cavum verge. Ghana Med J 47(1): 46-49
17. Yamada S, Goto T, Mccomb JG (2013) Use of a spin-labeled cerebrospinal fluid magnetic resonance imaging technique to demonstrate successful endoscopic fenestration of an enlarging symptomatic cavum septi pellucidi. World Neurosurg 80(3-4):436.e15-436.e18

18. Gangemi M, Donati P, Maiuri F, Sigona L (1997) Cyst of the velum interpositum treated by endoscopic fenestration. Surg Neurol 47(2): 134-136

19. Dandy WE (1931) Congenital cerebral cysts of the cavum septi pellucidi (fifth ventricle) and cavum vergae (sixth ventricle). Diagnosis and treatment. Arch Neurol Psychiatr 25:44-66

20. Echternacht AP, Campbell JA (1946) Mid-line anomalies of the brain; their diagnosis by pneumoencephalography. Radiology. 46:119-131

21. Heiskanen O (1973) Cyst of the septum pellucidum causing increased intracranial pressure and hydrocephalus. Case report. J Neurosurg 38(6):771-773

22. Krauss JK, Mundinger F (1997) Cavum septum pellucidum cysts. J Neurosurg 87(2):337-338

23. Miyamori T, Miyamori K, Hasegawa T, Tokuda K, Yamamoto Y (1995) Expanded cavum septi pellucidi and cavum vergae associated with behavioral symptoms relieved by a stereotactic procedure: case report. Surg Neurol 44(5):471-475

24. Bayar MA, Gökçek C, Gökçek A, Edebali N, Buharali Z (1996) Giant cyst of the cavum septi pellucidi and cavum vergae with posterior cranial fossa extension: case report. Neuroradiology. 38(Suppl 1):S187-S189

25. Meng H, Feng H, Le F, Lu JY (2006) Neuroendoscopic management of symptomatic septum pellucidum cysts. Neurosurgery. 59(2):278-283

26. Lancon JA, Haines DE, Raila FA, Parent AD, Vedanarayanan VV (1996) Expanding cyst of the septum pellucidum. Case report. J Neurosurg 85(6):1127-1134

27. Lancon JA, Haines DE, Lewis AI, Parent AD (1999) Endoscopic treatment of symptomatic septum pellucidum cysts: with some preliminary observations on the ultrastructure of the cyst wall: two technical case reports. Neurosurgery. 45(5):1251-1257

28. Sayama CM, Harnsberger HR, Couldwell WT (2006) Spontaneous regression of a cystic cavum septum pellucidum. Acta Neurochir 148(11):1209-1211

29. Kenan K et al (2007) Colloid cyst in cavum septum pellucidi: rare location and endoscopic removal. J Neurol Sci 24(4):326-330

30. Milligan BD, Meyer FB (2010) Morbidity of transcallosal and transcortical approaches to lesions in and around the lateral and third ventricles: a single-institution experience. Neurosurgery. 67(6):1483-1496

31. Weyerbrock A, Mainprize T, Rutka JT (2006) Endoscopic fenestration of a symptomatic cavum septum pellucidum: technical case report. Neurosurgery 59(4 Suppl 2):ONSE491

32. Krejčí T, Vacek P, Krejčí O, Chlachula M, Szathmaryová S, Lipina R (2019) Symptomatic cysts of the cavum septi pellucidi, cavum vergae and cavum veli interpositi: a retrospective duocentric study of 10 patients. Clin Neurol Neurosurg 185:105494

33. Donauer E, Moringlane JR, Ostertag CB (1986) Cavum vergae cyst as a cause of hydrocephalus, "almost forgotten"? Successful stereotactic treatment. Acta Neurochir 83(1-2):12-19

34. Wang L, Ling SY, Fu XM, Niu CS, Qian RB (2013) Neuronavigation-assisted endoscopic unilateral cyst fenestration for treatment of symptomatic septum pellucidum cysts. J Neurol Surg A Cent Eur Neurosurg 74(4):209-215

35. Lauretti L, Mattogno PP, Bianchi F, Pallini R, Fernandez E, Doglietto F (2015) Treatment of giant congenital cysts of the midline in adults: report of two cases and review of the literature. Surg Neurol Int 6(Suppl 13):S371-S374

Publisher's note Springer Nature remains neutral with regard to jurisdictional claims in published maps and institutional affiliations. 